\title{
ТРАНСФОРМАЦИЯ РОЛИ АВСТРИИ ВО ВНЕШНЕЭКОНОМИЧЕСКИХ СВЯЗЯХ ЧЕХИИ
}

\begin{abstract}
Аннотация. Статья посвящена анализу австрийско-чешских экономических отношений после вступления Чехии в ЕС. Автором дается оценка позиций Австрии и Чехии во внешнеторговом секторе другу друга с учетом динамики торговли и трансформации отраслевой структуры. Делается вывод об ослаблении позиций Австрии в чешской внешней торговле и о стабильности чешской роли как одного из основных партнеров Австрии в Центральной и Восточной Европе на фоне долгосрочной позитивной динамики взаимной торговли. Особое внимание уделяется австрийско-чешским инвестиционным связям: оцениваются тенденции накопленных ПИИ, трансформация их отраслевой структуры, обосновывается неравенство стран-партнеров. Дается характеристика присутствия австрийского капитала в Чехии не только с точки зрения общих тенденций, но и на примере отдельных компаний промышленности и сферы услуг. Автором выявляется ограниченность чешских ПИИ в Австрии и их неустойчивость. В статье указывается на сохранение различий в позициях Австрии и Чехии в торговой и инвестиционной сферах страны-партнера, обозначаются их причины.
\end{abstract}

Ключевые слова: Австрия, Чехия, внешняя торговля, ПИИ, отраслевая структура, ТНК.

Несмотря на то что политические отношения двух стран нельзя отнести к долгосрочно стабильным, Австрия играет значимую роль во внешнеэкономических связях Чехии: страна на протяжении долгого периода входит в десятку важнейших внешнеторговых партнеров Чехии, а также является одним из крупнейших инвесторов чешской экономики. Как и в случае других восточноевропейских стран, Чехия стала привлекать инвесторов из более развитых европейских государств, среди которых была и Австрия, еще в 1990-е гг. Постепенно Австрия превратилась в одного из ключевых внешнеторговых партнеров Чехии, однако вступление Чехии в Евросоюз и тем самым расширение возможностей для чешского экспорта ослабили австрийские позиции: внешнеторговый сектор Чехии переориентировался на все развитые страны-члены ЕС, а также на партнеров по Вишеградской группе и ряд других государств. Географическая близость Австрии и Чехии, размер австрийской

(C) Четверикова Анна Сергеевна - кандидат экономических наук, старший научный сотрудник ИМЭМО им. Е.М. Примакова РАН. Адрес: 117997, Москва, ГСП-7, ул. Профсоюзная, 23. E-mail: chetverikova.anna@gmail.com. 
экономики не смогли пересилить такие факторы, как расширение возможностей торговли с другими странами. Свою роль сыграли и негативные факторы, к числу которых относится и транспортная инфраструктура, соединяющая две страны и недостаточная для интенсификации чешско-австрийских отношений.

\section{Австрийско-чешские торговые отночения}

Диверсификация торговых потоков до сих пор является актуальной задачей для внешнеторгового сектора Чехии [Ministry..., 2017], чья экономика основана на внешнем спросе на производимые товары и значительной роли ТНК. Чехия, несмотря на небольшое снижение показателей за последние два года, продолжает отличаться повышенной долей экспорта и импорта в ВВП, характерной для небольших экономик: в 2016 г. экспорт составил более 79,5\% ВВП Чехии, импорт - 72,1\% ВВП [Всемирный банк, 2016]. Тем самым чешская экономика остается сильно зависимой от внешнеэкономической конъюнктуры, при условии, что экспорт выступает главной движущей силой экономики страны [Дрыночкин, 2016: 78].

Чешская Республика, принимая во внимание собственную чрезмерную зависимость от европейского рынка, стремится диверсифицировать товарные потоки за счет крупных рынков, преимущественно вне EC, к которым относятся, например, российское и китайское направления. Однако пока ей это не очень удается: основными экономическими партнерами остаются страны-члены ЕС при главенствующей роли Германии благодаря присутствию немецкого капитала в чешской экономике. Так, основные внешнеторговые партнеры Чехии по импорту - это Германия, Китай, Польша, а также Словакия, Италия, Франция, Нидерланды, Великобритания, Россия; по экспорту - Германия, Словакия и Польша, а также Франция, Великобритания, Италия, Нидерланды, Венгрия и Испания. Австрия стабильно входит в десятку лидеров по экспорту и импорту Чехии, хотя ее доля как в экспорте Чехии, так и в импорте со времени вступления Чехии в ЕС сократилась (табл. 1).

Если сравнивать важность Австрии и Чехии как внешнеторговых партнеров друг для друга, то Чехия играет более важную роль для Австрии, являясь при этом и основным торговым партнером Австрии в Центральной Европе в целом [Stehrer, Stöllinger, 2013: 19]. Чешская Республика практически стабильно является пятым рынком сбыта австрийского импорта. Кроме нее, партнерами Австрии по импорту являются Германия, Италия, Китай, а также Швейцария, США, Нидерланды, Франция, Венгрия. Чешские позиции в экспорте чуть слабее, однако также стабильны. Шестое место среди партнеров по экспорту обеспечивает Чехии чуть менее $4 \%$ от экспортных поставок из Австрии, при этом эта доля имела тенденцию к росту с 2005 г. Австрийские экспортные поставки направляются также в Германию, Италию, США, Францию, Швейцарию, Польшу, Венгрию, Великобританию, Китай. 
Таблица 1.

Позиции Австрии и Чехии во внешней торговле друг друга, \%

\begin{tabular}{|l|c|c|c|c|c|}
\hline \multicolumn{1}{|c|}{ Показатель } & $\mathbf{2 0 0 5}$ г. & $\mathbf{2 0 1 0}$ г. & $\mathbf{2 0 1 5}$ г. & $\mathbf{2 0 1 6}$ г. & $\mathbf{2 0 1 7}$ г. \\
\hline $\begin{array}{l}\text { Место/ доля Чехии в } \\
\text { экспорте Австрии }\end{array}$ & $8 / 3,1$ & $6 / 3,8$ & $6 / 3,6$ & $6 / 3,7$ & $6 / 3,7$ \\
\hline $\begin{array}{l}\text { Место/ доля Чехии в } \\
\text { импорте Австрии }\end{array}$ & $5 / 3,3$ & $5 / 3,7$ & $5 / 4,2$ & $5 / 4,3$ & $5 / 4,3$ \\
\hline $\begin{array}{l}\text { Место/ доля Авст- } \\
\text { рии в экспорте Че- } \\
\text { хии }\end{array}$ & $3 / 5,6$ & $6 / 4,7$ & $6 / 4,1$ & $7 / 4,2$ & $6 / 4,4$ \\
\hline $\begin{array}{l}\text { Место/ доля Авст- } \\
\text { рии в импорте Че- } \\
\text { хии }\end{array}$ & $8 / 4,0$ & $7 / 3,4$ & $8 / 3,0$ & $7 / 2,9$ & $8 / 2,9$ \\
\hline
\end{tabular}

Источники: Statistik Austria (http://www.statistik.at); the Czech Statistical Office (www.czso.cz).

В 2017 г. товарооборот между Чехией и Австрией превысил 11 млрд евро (табл. 2). При увеличении с момента вступления Чехии в ЕС товарооборота австрийскочешской торговли практически вдвое его динамика не всегда была положительной. Основное сокращение пришлось на период мирового финансово-экономического кризиса, когда экспорт Чехии сократился почти на 20\%, а импорт - на $23 \%$, практически повторив общую тенденцию внешнеторговых потоков Чехии. Сокращение импорта и экспорта отмечалось и в 2013 г., когда наблюдался спад в чешской экономике. Подъем экономики Чехии в последние годы и особенно результаты 2017 г. повлияли и на улучшение динамики австрийско-чешской торговли, когда рост превысил $12 \%$. Характерной чертой торговых связей Чехии и Австрии остается и положительное сальдо торгового баланса Чехии, которое продолжает увеличиваться, уже более чем удвоившись с 2005 г., благодаря более активному наращиванию экспортных поставок в Австрию.

Таблица 2.

Динамика австрийско-чешской торговли

\begin{tabular}{|l|c|c|c|c|c|}
\hline Показатель & $\mathbf{2 0 0 5}$ г. & $\mathbf{2 0 1 0}$ г. & $\mathbf{2 0 1 5}$ г. & $\mathbf{2 0 1 6}$ г. & $\mathbf{2 0 1 7}$ г. \\
\hline $\begin{array}{l}\text { Товарооборот, млрд } \\
\text { евро }\end{array}$ & 5,97 & 7,96 & 9,59 & 9,98 & 11,23 \\
\hline Индекс роста, \% & 109,5 & 121,8 & 103,1 & 104,1 & 112,5 \\
\hline Экспорт, млрд евро & 3,52 & 4,74 & 5,79 & 6,23 & 7,05 \\
\hline Индекс роста, \% & 108,1 & 125,1 & 101,8 & 107,5 & 113,1 \\
\hline Импорт, млрд евро & 2,45 & 3,22 & 3,79 & 3,75 & 4,18 \\
\hline Индекс роста, \% & 111,6 & 117,2 & 104,9 & 98,8 & 111,5 \\
\hline Сальдо, млрд евро & 1,07 & 1,52 & 2,00 & 2,48 & 2,87 \\
\hline
\end{tabular}

Источник. The Czech Statistical Office (www.czso.cz). 
В целом, по данным 2017 г., чешский экспорт в Австрию обеспечивают всего три сектора, которые были его основой и в середине 2000-х гг., - машины и оборудование, дающие более $40 \%$ экспорта в Австрию, промышленные товары (около $16 \%$ ) и прочие промышленные товары (около 16\%). Однако членство в ЕС все же внесло некоторые коррективы в отраслевую структуру экспортных поставок в Австрию.

Во-первых, можно отметить возрастание роли машиностроительного сектора, в том числе за счет диверсификации поставляемой продукции. Так, в основные экспортные статьи вошли поставки офисной техники, а также телекоммуникационного оборудования. При этом часть позиций машиностроительного сектора ушла из числа основных экспортных групп (табл. 3). Во-вторых, в силу структурных изменений в самой экономике Чехии из экспорта исчез ряд сырьевых подотраслей, к которым относятся в том числе и поставки угля, обеспечивавшие около 7\% чешского экспорта в Австрию еще в середине 2000-х гг. В-третьих, увеличились поставки в рамках потребительского сектора, включая обувную продукцию, одежду.

В результате рассматриваемые семь позиций, являвшиеся основой экспорта Чехии в Австрию в середине 2000 -х гг., в настоящее время обеспечивают около $42 \%$ чешского экспорта в Австрию (в 2005г. - 48,8\%).

Таблица 3.

Отраслевая структура австрийско-чешской торговли товарами, \%

\begin{tabular}{|c|c|c|c|c|c|}
\hline Сектора & 2005 г. & 2010 г. & 2015 г. & 2016 г. & 2017 r \\
\hline Экспорт, всего & 100 & 100 & 100 & 100 & 100 \\
\hline $\begin{array}{l}\text { в том числе } \\
\text { • электрооборудование } \\
\text { - транспортные средства } \\
\text { • уголь } \\
\text { • металлические изделия } \\
\text { • дерево } \\
\text { - энергетическое обору- } \\
\text { дование } \\
\text { - оборудование общего } \\
\text { назначения }\end{array}$ & $\begin{array}{c}12,5 \\
10,5 \\
6,7 \\
6,4 \\
4,9 \\
4,3 \\
3,5\end{array}$ & $\begin{array}{c}10,0 \\
10,6 \\
6,1 \\
5,5 \\
5,0 \\
1,1 \\
4,4\end{array}$ & $\begin{array}{c}9,7 \\
13,4 \\
1,3 \\
6,0 \\
5,0 \\
1,2 \\
4,8\end{array}$ & $\begin{array}{c}10,0 \\
13,4 \\
1,1 \\
6,0 \\
5,4 \\
1,3 \\
5,2\end{array}$ & $\begin{array}{c}9,1 \\
14,1 \\
1,1 \\
6,0 \\
5,4 \\
1,3 \\
5,2\end{array}$ \\
\hline Импорт, всего & 100 & 100 & 100 & 100 & 100 \\
\hline $\begin{array}{l}\text { в том числе } \\
\text { • нефть, нефтепродукты } \\
\text { • электрооборудование } \\
\text { • чугун, сталь } \\
\text { • оборудование общего } \\
\quad \text { назначения } \\
\text { • металлические изделия } \\
\text { • транспортные средства }\end{array}$ & $\begin{array}{l}9,6 \\
9,6 \\
8,1 \\
6,5 \\
5,2 \\
4,8\end{array}$ & $\begin{array}{c}6,1 \\
10,2 \\
8,6 \\
4,1 \\
5,5 \\
4,5\end{array}$ & $\begin{array}{l}4,8 \\
8,4 \\
8,3 \\
5,7 \\
5,4 \\
6,0\end{array}$ & $\begin{array}{l}4,9 \\
8,7 \\
8,1 \\
5,3 \\
5,2 \\
5,8\end{array}$ & $\begin{array}{c}4,2 \\
10,2 \\
9,0 \\
4,5 \\
5,2 \\
5,7\end{array}$ \\
\hline
\end{tabular}

Источник. Czech statistical office. External trade database
(http://apl.czso.cz/pll/stazo/STAZO.STAZO?jazyk=EN). 
Отраслевая структура импорта из Австрии мало изменилась с момента вступления Чехии в ЕС: лидирующие позиции за собой сохранили сектор машин и оборудования, обеспечивающий более $31 \%$ чешских закупок в Австрии, и промышленные товары (более $27 \%$ в 2017 г.). Более подробное рассмотрение чешского импорта показывает (табл. 3). В его структуре сократилась доля сырья, что соответствует общемировой тенденции. Сократилась и доля отдельных видов оборудования, однако это было компенсировано ростом другой машиностроительной продукции. Относительно стабильными остаются поставки металлургической продукция для нужд машиностроительного и металлургического комплексов Чехии. В настоящее время в совокупности на шесть рассматриваемых позиций приходится около $38 \%$ всего чешского импорта из Австрии (в 2005 г. - 43,8\%). За пределами основных групп импортируемых товаров в современных чешских поставках из Австрии также большую роль играет такая продукция, как бумага, специализированное оборудование, цветные металлы, фармацевтическая продукция, что позволяет говорить о том, что чешский импорт стал более диверсифицированным.

Таким образом, в последние годы внешнеторговые связи Австрии и Чехии продолжают развиваться путем наращивания объемов взаимной торговли, а также трансформации ее отраслевой структуры. При этом на обоюдной торговле уже сказались усилия чешских властей по диверсификации экспортных поставок, что вывело Австрию из числа пятерки основных экспортных партнеров Чехии.

\section{Инвестиционные связи Чехии и Австрии}

$\mathrm{C}$ точки зрения инвестиционных отношений Чехия и Австрия являются неравными партнерами. В определенной степени это обусловливается различиями в инвестиционной привлекательности этих государств. Согласно индексу законодательных ограничений ПИИ ОЭСР Чехия является пятой страной по открытости и отсутствию ограничений в отношении иностранных инвесторов, в то время как Австрия занимает лишь 41-ю позицию, хотя и Австрия, и Чехия за последние годы сделали многое для смягчения подобных ограничений [Thomsen, Mistura, 2017]. Чехия в целом как представитель Вишеградской группы более ориентирована на внешние источники экономического роста и характеризуется высоким уровнем открытости экономики, что предопределяет ее участие в структурах европейских ТНК [Габарта, 2017: 106-107].

По размеру накопленных ПИИ Чехия находится за пределами двадцатки крупнейших инвесторов австрийской экономики, в то время как Австрия относится к основным странам - поставщикам ПИИ в экономику Чехии. При этом и для Чехии, и для Австрии одним из важнейших партнеров является Германия. По размерам накопленных ПИИ позиции стран отличаются в разы (табл. 4), хотя с момента вступления Чехии в ЕС чешские инвестиции в Австрию увеличивались быстрее, чем аналогичные австрийские вложения. По итогам 2016 г. австрийские ПИИ в Чехии даже продемонстрировали падение - минус $4,1 \%$. Подъем чешской экономики и относительно стабильное развитие в последние годы позволили укрепить чеш- 
ские позиции и на австрийском рынке: рост в 2015 г. составил более 8,5 раза, в 2016 г. $-8,3 \%$, хотя накопленные чешские ПИИ настолько малы, что их динамику может определять несколько крупных сделок.

Таблица 4.

Накопленные ПИИ Австрии и Чехии, млн евро

\begin{tabular}{|l|c|c|c|c|c|c|}
\hline \multicolumn{1}{|c|}{ Показатель } & $\begin{array}{c}\text { На конец } \\
\mathbf{2 0 0 0} \text { г. }\end{array}$ & $\begin{array}{c}\text { На конец } \\
\mathbf{2 0 0 5} \text { г. }\end{array}$ & $\begin{array}{c}\text { На конец } \\
\mathbf{2 0 1 0} \text { г. }\end{array}$ & $\begin{array}{c}\text { На конец } \\
\mathbf{2 0 1 4} \text { г. }\end{array}$ & $\begin{array}{c}\text { На конец } \\
\mathbf{2 0 1 5} \text { г. }\end{array}$ & $\begin{array}{c}\text { На конец } \\
\mathbf{2 0 1 6} \text { г. }\end{array}$ \\
\hline $\begin{array}{l}\text { Накопленные } \\
\text { ПИИ Австрии в } \\
\text { Чехии }\end{array}$ & 2105 & 4937 & 10413 & 12020 & 13225 & 12688 \\
\hline $\begin{array}{l}\text { Накопленные } \\
\text { ПИИ Чехии в } \\
\text { Австрии }\end{array}$ & 4 & 1 & 10 & 21 & 181 & 196 \\
\hline
\end{tabular}

Источник. The Oesterreichische Nationalbank (https://www.oenb.at).

Хотя чешские власти высказывали свое недовольство относительно отраслевой структуры поступающих иностранных инвестиций еще в середине 2000 -х гг. и намеревались увеличить вложения в первую очередь в научно-исследовательский сектор и сферу новых технологий [Четверикова, 2013: 151], отраслевая структура ПИИ не претерпела кардинальных изменений. Наиболее привлекательными сферами для иностранных инвесторов остались финансовое посредничество (27\% от общего объема накопленных ПИИ в 2016 г.), торговля (10,3\%), недвижимость $(8,2 \%)$, хотя научно-исследовательский сектор $(5,5 \%)$ и ИТ-сфера $(5,8 \%)$ значительно улучшили свои позиции с точки зрения инвестиционной привлекательности и вошли в число лидеров, обогнав многие отрасли вторичного сектора. В рамках промышленности наибольший объем ПИИ вкладывался в автомобилестроение, химическую и пищевую промышленность, металлургию [Czech national bank, 2017]. При этом контроль над чешскими отраслями со стороны иностранных инвесторов различен. Одним из наиболее подконтрольных иностранному капиталу секторов остается, например, банковский сектор, где свою роль играет и австрийский капитал [Dubská, 2012].

Отраслевая структура австрийских накопленных ПИИ в Чехии (табл. 5) в целом совпадает с традиционной для Чехии, однако имеет свои особенности в силу характеристик самих австрийских компаний. По причине развитости банковских и других финансовых структур в Австрии, которые ведут активную деятельность на внешних рынках, в структуре накопленных ПИИ Австрии в Чехии сильно превалирует финансовое посредничество. Можно сказать, что финансовый сектор и ряд отраслей промышленности являются «традиционными» для австрийских ПИИ, направляемых в страны Восточной Европы [Кузнецов и др., 2017: 39-42]. Недвижимость и торговля также относятся к наиболее привлекательным секторам для австрийских инвесторов, однако роль торгового сектора постепенно снижается. При этом стоит отметить, что изначально, начиная с 1989 г., на рынках восточноевро- 
пейских стран наибольшую инвестиционную активность проявляли австрийские компании торгового сектора, финансовой и страховой сферы, а также строительства, заинтересованные в завоевании местных рынков [Altzinger, 1998: 15]. Как показывает чешская статистика, постепенно снижается и доля сырьевых отраслей промышленности, являющихся традиционными для австрийских вложений. На этом фоне увеличивается значимость отдельных подотраслей машиностроения, а также научно-исследовательского сектора.

Таблица 5.

Отраслевая структура накопленных ПИИ Австрии в Чехии, \%

\begin{tabular}{|l|c|c|c|c|c|}
\hline \multicolumn{1}{|c|}{ Сектор } & $\mathbf{2 0 0 5}$ г. & $\mathbf{2 0 1 0}$ г. & $\mathbf{2 0 1 4}$ г. & $\mathbf{2 0 1 5}$ г. & $\mathbf{2 0 1 6}$ г. \\
\hline $\begin{array}{l}\text { Финансовое посредниче- } \\
\text { ство }\end{array}$ & 48,1 & 54,4 & 61,8 & 63,6 & 57,6 \\
\hline Недвижимость & 7,8 & 8,7 & 7,8 & 7,3 & 7,9 \\
\hline Торговля & 9,7 & 9,5 & 5,7 & 5,2 & 5,9 \\
\hline $\begin{array}{l}\text { Химическая промышлен- } \\
\text { ность }\end{array}$ & 8,5 & 3,4 & 3,3 & 3,4 & н.Д. \\
\hline $\begin{array}{l}\text { Целлюлозно-бумажная, } \\
\text { деревообрабатывающая } \\
\text { промышленность }\end{array}$ & 4,5 & 1,0 & 2,8 & н.д. & н.д. \\
\hline Автомобилестроение & 0,3 & 1,1 & 1,3 & 2,2 & 2,6 \\
\hline $\begin{array}{l}\text { Научно- } \\
\text { исследовательский сектор }\end{array}$ & н.д. & 0,4 & 0,7 & н.д. & 1,3 \\
\hline Прочие & 21,1 & 21,5 & 16,6 & 18,3 & 24,7 \\
\hline Итого & 100 & 100 & 100 & 100 & 100 \\
\hline
\end{tabular}

Источник. Czech national bank (https://www.cnb.cz).

Благодаря тому что Австрия наряду с Германией и Нидерландами на протяжении долгого времени входит в число крупнейших иностранных инвесторов чешской экономики, австрийские компании играют важную роль на чешском рынке труда. В настоящее время в австрийских компаниях в Чехии работает 94,5 тыс. человек [The Oesterreichische Nationalbank, 2016], что составляет 1,8\% от всего занятого населения страны. За последние 10 лет австрийские инвесторы увеличили число рабочих мест в Чехии более чем в 1,5 раза, что обеспечило Чехии лидирующее место по числу рабочих мест, созданных инвесторами из Австрии в зарубежных странах.

Всего в Чехии действует около 2000 австрийских компаний, крупнейшими из которых являются Erste Bank, различные структуры группы Raiffeisen, Vienna Insurance Group. За пределами третичного сектора выделяются REWE International, Strabag, Wienerberger и ряд других. Многие компании ведут свою деятельность в столичном регионе как традиционно наиболее привлекательном во многих странах, однако уровень заработной платы, инвестиции в научно-исследовательскую базу и ряд других факторов предопределяют инвестирование и в другие чешские регионы [Babuněk, 2017]. 
Австрийские ПИИ поступают в Чехию как в форме создания новых подразделений, так и в форме покупки существующих активов. Например, в 2010 г. австрийская Lenzing приобрела за 87 млн евро 75\% производителя целлюлозы Biocel Paskov, впоследствии доведя свой пакет до $100 \%{ }^{1}$. За годы владения активом Lenzing модернизировала производство, вложив несколько десятков миллионов евро. В 2016-2019 гг. компания инвестирует еще 40 млн евро в расширение мощностей [Lenzing, 2016]. До 2010 г. чешский завод около 10 лет принадлежал другой австрийской компании, инвестировавшей в его развитие и выстроившей производственные связи с австрийской Mayr-Melnhof как поставщиком сырья.

Производитель строительных материалов Wienerberger владеет в Чехии более чем десятью заводами. Компания активно расширяла свое присутствие еще в начале 2000-х гг. В частности, в 2004 г. ею было приобретено три кирпичных завода, а в 2005 г. Wienerberger запустил еще один кирпичный завод, инвестировав в его создание 23,5 млн евро [Wienerberger, 2004].

Австрийские банки продолжают занимать устойчивые позиции в Чехии, заинтересовавшись чешским рынком еще до вступления страны в ЕС. Tак, Česká spořitelna, принадлежащий Erste Bank, входит в число ведущих розничных банков страны с почти 5 млн клиентов и 620 подразделениями. За последние 5 лет банк увеличил собственный капитал более чем на 20\%: с 3,7 млрд евро в 2012 г. до 4,5 млрд евро в 2016 г. [Česká spořitelna, 2016]. Перспективным чешский рынок считает и Raiffeisen: только банк группы, действующий в Чехии с начала 1990-х гг., увеличил собственный капитал за 5 лет на 28,5\% - до 928 млн евро [Raiffeisen bank, 2016]. В свою очередь Vienna Insurance Group владеет 4 страховыми компаниями в Чехии, где работает около 5 тыс. человек, и занимает около $33 \%$ рынка.

Чешское присутствие в Австрии достаточно ограниченно как по объемам вложений, так и по отраслевой структуре. Всего около 300 чешских фирм ведут свою деятельность в Австрии. Среди прямых инвесторов превалируют представительства, однако часть чешских компаний владеет и более значимыми активами в Австрии. Например, чешская строительная компания Metrostav в 2013 г. приобрела BeMo Tunnelling, специализирующуюся на строительстве туннелей и туннельном оборудовании. Производитель напитков Karlovarske mineralní vody в 2007 г. купил $25,1 \%$ второго по величине производителя минеральной воды и безалкогольных напитков Австрии - Waldquelle Kobersdorf. Однако одним из крупнейших вложений последних лет является покупка Sazka Group доли австрийского игрового опеpaтopa Casinos Austria, владеющего 12 казино в Австрии и 26 казино в других странах мира. Первоначально чешская компания приобрела $11 \%$, но впоследствии, в 2015-2016 гг., увеличила свой пакет до 34\%, который оценивается более чем в 200 млн евро. Тем самым чешские компании только после вступления страны в ЕС стали инвестировать в австрийские активы, при этом многие вложения осуществляются через покупку действующих активов, а не путем создания новых. В целом Австрия не является одним из основных направлений чешской инвестиционной экспан-

${ }^{1}$ В 2012 г. 25\% Biocel Paskov было приобретено за 26 млн евро. Современная Европа, 2018, № 7 
сии, скорее, это одно из направлений экспансии компаний Чехии в ближайших странах-соседях наряду с Германией, Словакией, Венгрией и другими странами.

После вступления Чехии в ЕС австрийско-чешские внешнеэкономические связи претерпели ряд изменений, однако Австрия остается важным внешнеэкономическим партнером Чехии, что проявляется как в торговой, так и в инвестиционной сфере. При росте объемов взаимной торговли увеличивается сальдо торгового баланса Чехии на фоне некоторого снижения позиций Австрии во внешнеторговом секторе Чехии, особенно в экспорте. Трансформируется и отраслевая структура торговли, но ключевые позиции в торговле товарами остаются за машиностроительной продукцией. В настоящее время можно говорить о том, что Чехия играет бо́льшую роль в австрийском внешнеторговом секторе, чем Австрия в чешской торговле, что обусловлено в том числе сменой экспортных приоритетов Чешской Республики. В сфере взаимных ПИИ, напротив, наблюдается обратная ситуация: Австрия играет более значительную роль как инвестор в чешской экономике. Более развитая экономика, наличие ТНК, заинтересованных в экспансии на рынках Центральной и Восточной Европы, обусловили долгосрочное и масштабное присутствие австрийского капитала в Чехии. Отраслевая специализация австрийских ТНК повлияла и на относительно нестандартную структуру вложений в Чехию: сильное превалирование третичного сектора. В свою очередь чешский капитал в силу отсутствия собственных крупных ТНК и конкуренции со стороны крупных транснациональных корпораций других стран, а также вследствие продолжающихся трансформационных процессов в чешской экономике и ряда других факторов лишь в последние годы стал проникать в Австрию. Однако накопленный объем чешских ПИИ в Австрии позволяет говорить о нестабильности современной картины инвестирования и возможности ее изменения при ухудшении экономической ситуации.

\section{Список литературы}

Всемирный Банк (2016), Indicators. [online]. Available at: http://data.worldbank.org/indicator (accessed 03.04.2018).

Габарта, А.А. (2017), “Социально-экономическая модель стран Центральной Европы”, Современная Европа, №7(79), сс. 104-113.

Дрыночкин, А.В. (2016), Экономика Чехии и Словакии, МГИМО Университет, Москва.

Кузнецов, А.В., Володин, А.Г., Володина (2017), ЕАЭС и страны Евразийского континента: мониторинг и анализ прямых инвестиций 2017, ЦИИ ЕАБР, СПб.

Четверикова, А.С. (2013), “Чехия: пример довольно благополучного нового члена ЕС”, в Кузнецов, А.В. и Хесин, Е.С. (ред.), Экономика стран ЕС после введения евро: от эйфории 1999 г. до долгового кризиса 2010-х годов, ИМЭМО РАН, Москва, Россия, сс. 145-156.

Altzinger, W. (1998), Austria's foreign direct investment in Central and Eastern Europe: «supply based» or market driven? Department of Economics Working Paper Series, 57. Available at: http://epub.wu.ac.at/1566/ (accessed 03.04.2018).

Babuněk, O. (2017), "Selected factors determining inward of foreign direct investment in the Czech regions in years 2002 to 2012", Statistika, № 97(3), pp. 16-34. 
Česká spořitelna (2016), Výroční zpráva 2016. [online]. Available at: https://www.csas.cz/static_internet/cs/Obecne_informace/FSCS/CS/Prilohy/vz_2016.pdf (accessed 03.04.2018).

Czech national bank (2017), Foreign investment data 2014-2017. [online]. Available at: https://www.cnb.cz/analytics/saw.dll?Portal (accessed 03.04.2018).

Dubská, D. (2012), “Foreign controlled companies in the Czech economy”, Statistika, №49(2), pp. 4-28.

Lenzing Group (2016), Annual report 2016. [online]. Available at: https://www.lenzing.com/fileadmin/content/PDF/07_Finanzen/Geschaeftsberichte/EN/GB_2016_EN.pdf (accessed 03.04.2018).

Ministry of Foreign Affaires of the Czech Republic, Ministry of industry and trade. (2017), Updating the Export strategy of the Czech Republic 2012-2020. Available at: https://www.mpo.cz/assets/en/foreigntrade/support-for-export/conception-and-strategy/2017/4/updating-Export-Strategy.pdf 03.04.2018).

Raiffeisen bank (2016), Annual report 2016. [online]. Available at: https://www.rb.cz/attachments/vyrocni\%20zpravy/vz-rb-16-en.pdf (accessed 03.04.2018).

Stehrer, R. and Stöllinger, R. (2013), Positioning Austria in the global economy: value added trade, international production sharing and global linkages, FIW Research Reports series V-002, FIW.

The Oesterreichische Nationalbank (2016), Statistics, Foreign direct investment [online]. Available at: https://www.oenb.at/en/Statistics/Standardized-Tables/external-sector/foreign-direct-investment.html (accessed 03.04.2018).

Thomsen, S. and Mistura, F. (2017), Is investment protectionism on the rise?/ Evidence from the OECD FDI Regulatory Restrictiveness Index. Available at: http://www.oecd.org/investment/globalforum/2017-GFIIBackground-Note-Is-investment-protectionism-on-the-rise.pdf (accessed 03.04.2018).

Wienerberger (2004), Czech Republic: Wienerberger continues expansion. 25.08.2004. [online]. Available at: https://www.wienerberger.com/czech-republic-wienerberger-continues-expansion.html (accessed 03.04.2018).

\section{References}

Altzinger, W. (1998), Austria's foreign direct investment in Central and Eastern Europe: «supply based» or market driven? Department of Economics Working Paper Series, 57. Available at: http://epub.wu.ac.at/1566/ (accessed 03.04.2018).

Babuněk, O. (2017), "Selected factors determining inward of foreign direct investment in the Czech regions in years 2002 to 2012”, Statistika, №97(3), pp. 16-34. $\begin{array}{ccccc}\text { Česká spořitelna } & \text { (2016), } & \text { Výroční zpráva } & \text { 2016. [online]. } & \text { Available at: } \\ \text { https://www.csas.cz/static_internet/cs/Obecne_informace/FSCS/CS/Prilohy/vz_2016.pdf } & \text { (accessed }\end{array}$ 03.04.2018).

Chetverikova, A.S. A.C. (2013), "The Czech republic: an example of a fairy prosperous new member of the EU”, in Kuznetsov, A.V. and Hesin, E.S. (ed.), Jekonomika stran ES posle vvedenija evro: ot jejforii 1999 g. do dolgovogo krizisa 2010-h godov [EU member states economies after the introduction of the euro: from euphoria of 1999 to the debt crisis of the 2010s], ИМЭМО РАН, Москва, Россия, pp. 145-156.

Czech national bank (2017), Foreign investment data 2014-2017. [online]. Available at: https://www.cnb.cz/analytics/saw.dll?Portal (accessed 03.04.2018).

Drynochkin, A.V. (2016), Jekonomika Chehii i Slovakii [The economy of the Czech Republic and Slovakia], MGIMO University, Moscow.

Dubská, D. (2012), "Foreign controlled companies in the Czech economy”, Statistika, №49(2), pp. 4-28.

Habarta, A.A. (2017), "Social and economic model of Central European countries", Contemporary Europe, №7(79), pp. 104-113.

Kuznetsov, A., Volodin, A., Volodina, M., Gemuyeva, K., Gutnik, A., Kvashnin Y., Makarova, A., Nevskaya, A., Chetverikova, A., Tsukarev, T. (2017), EAJeS i strany Evrazijskogo kontinenta: monitoring i analiz prjamyh investicij 2017 [EAEU and Eurasia: Monitoring and Analysis of Direct Investments 2017], EDB Centre for Integration Studies, Saint Petersburg.

Современная Европа, 2018, № 7 


Lenzing Group (2016), Annual report 2016. [online]. Available at:
https://www.lenzing.com/fileadmin/content/PDF/07_Finanzen/Geschaeftsberichte/EN/GB_2016_EN.pdf
(accessed 03.04.2018).
Ministry of Foreign Affaires of the Czech Republic, Ministry of industry and trade. (2017), Updating the
Export strategy of the Czech Republic 2012-2020. Available at: https://www.mpo.cz/assets/en/foreign-
trade/support-for-export/conception-and-strategy/2017/4/updating-Export-Strategy.pdf
03.04.2018).

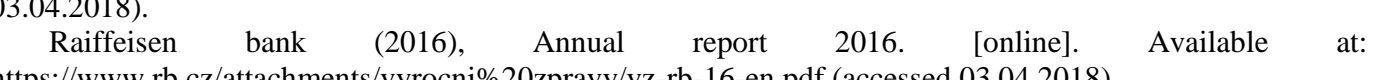
https://www.rb.cz/attachments/vyrocni\%20zpravy/vz-rb-16-en.pdf (accessed 03.04.2018).

Stehrer, R. and Stöllinger, R. (2013), Positioning Austria in the global economy: value added trade, international production sharing and global linkages, FIW Research Reports series V-002, FIW.

The Oesterreichische Nationalbank (2016), Statistics, Foreign direct investment [online]. Available at: https://www.oenb.at/en/Statistics/Standardized-Tables/external-sector/foreign-direct-investment.html (accessed 03.04.2018).

Thomsen, S. and Mistura, F. (2017), Is investment protectionism on the rise?/ Evidence from the OECD FDI Regulatory Restrictiveness Index. Available at: http://www.oecd.org/investment/globalforum/2017-GFIIBackground-Note-Is-investment-protectionism-on-the-rise.pdf (accessed 03.04.2018).

Wienerberger (2004), Czech Republic: Wienerberger continues expansion. 25.08.2004. [online]. Available at: https://www.wienerberger.com/czech-republic-wienerberger-continues-expansion.html (accessed 03.04.2018).

World Bank (2016), Indicators. Available at: http://data.worldbank.org/indicator (accessed 03.04.2018).

Transformation of Austria's Role in Foreign Economic Relations of the Czech Republic

Author. Chetverikova A., Cand. of Science (Economics), Senior Researcher, Centre for European Studies, Primakov Institute of World Economy and International Relations, Russian Academy of Sciences (IMEMO RAN), Address: IMEMO RAN 23, Profsoyuznaya Str., Moscow, 117997, Russian Federation. Email: chetverikova@imemo.ru.

Abstract. The article is devoted to an analysis of the Austrian-Czech economic relations after the Czech Republic's accession to the EU. The author evaluates positions of Austria and the Czech Republic in each other's foreign trade sector with the consideration of trade's dynamic and sectoral structure's transformation. The conclusion is drawn on the weakening of Austria's positions in Czech foreign trade and on Czech stable role as one of Austria's main partners in Central and Eastern Europe amid the long-term positive dynamics of mutual trade. Special attention is paid to the Austrian-Czech investment relations: trends of accumulated FDI and the transformation of FDI's sectoral structure are evaluated; the inequality of the partner countries is substantiated. The characteristic of Austrian capital's presence in the Czech Republic is given not only in terms of general trends, but also in case of individual companies in industry and services. The author reveals the limitations of Czech FDI in Austria and their instability. The article points to the preservation of differences in positions of Austria and the Czech Republic in trade and investment sectors of the partner countries; their causes are indicated.

Key words: Austria, the Czech Republic, foreign trade, FDI, sectoral structure, TNC

DOI: http://dx.doi.org/10.15211/soveurope72018165179190 